\title{
Plurality Overload and the Compulsion to Regress: A Conversation through Questions Victor Brar
}

In Teaching to Transgress, bell hooks (1994) writes: "When I first entered the multicultural, multiethnic, classroom setting I was unprepared. I did not know how to cope with so much 'difference'. Despite progressive politics, and my deep engagement with the feminist movement, I had never before been compelled to work within a truly diverse setting and I lacked the necessary skills. It is difficult for many educators in the United States to conceptualize how the classroom will look when they are confronted with the demographics which indicate that 'whiteness' may cease to be the norm ethnicity in classroom settings on all levels. Hence, educators are poorly prepared when we actually confront diversity. This is why so many of us stubbornly cling to old patterns" (p. 41).

hooks' thoughts accurately portray the struggle that I currently face with excessive plurality in my educational practice. Although she primarily refers to plurality in the cultural and ethnic sense, the plurality that I am concerned with is much broader in scope and in range. My class of twentyfive inner-city grade fours is not only diverse in terms of culture and ethnicity, but also in terms of learning preferences, languages, individualized academic programs, academic ability, physical ability, intellectual ability, emotional readiness, gender, individual motivation, socio-economic status, family situations, and parental involvement just to name a few. This picture becomes more complex when you consider that each individual student also possesses these traits in varying degrees. Much of the literature that I have read concerning diversity makes the general argument that students extract more meaning from an education that corresponds to their unique needs and validates their individuality. Although I agree with this argument, I am uncertain of how to make it happen in the practical sense given that there is so much diversity in my classroom. This situation causes me to feel that I am constantly thrust into a paralytic state of indecisiveness and unresponsiveness. The overload of plurality that I am faced with causes me 
to experience cognitive overload and therefore leaves me unable to process whose needs I should respond to now versus later, especially given that they are all urgent. Consequently, I feel as though I am unable to teach in a comprehensive, meaningful, and professional manner, but rather am forced out of a survivalist necessity to engage in a form of educational triage in which I manage to pay attention only to the immediate concerns of each student before quickly moving on to the next, without being able to address their larger educational picture.

To illustrate this situation using an alternative humorous metaphor (which is all I can do at this point to maintain some sanity), I feel as though I am being asked as a chef by my paradoxical and demanding restaurateur employer (the government) to simultaneously prepare a four course dinner (the curriculum) that meets the individual tastes of multiple individuals (my class) who all fancy a different type of cuisine (differentiated instruction) and have unique dietary needs (specific individual needs) and make it a success (high achievement). How is it possible as a single chef to satisfy the greatly varying culinary palates of thirty unique individuals simultaneously, and do so in one sitting? The enormity of grappling with what appears to be unlimited plurality compels me to regress into the comfort of familiar patterns rather than progress towards new ones. Further, I find myself asking, "At what point does addressing plurality just become too difficult to be achieved in a realistic manner?"

Given excessive diversity that exists in today's schools, and given that schools like mine are trying to cultivate cultures that stress a sense of community and belonging, how can this be achieved when so much emphasis is placed on "difference"? For example, the current norm in my school is that there is no norm. That is, the exception has become the norm. By highlighting the idea of plurality and individuality are we eroding any chance at developing a sense of community within our schools in which we can all share? In other words, is the focus on plurality actually more divisive than integrative? Take for example school clubs that are organized around various interests such as sports or ethnic affiliations. These clubs each have their own vested interests that usually do not intersect with those of others. Hence, these clubs by their very nature are segregated and membership is 
restricted to those who are the same. Fragmenting schools in such a way does more to contribute to misunderstanding and division than it does to the creation of a larger cohesive school culture. This leads me to ask, how do you simultaneously cultivate both plurality and commonality?

Next, I am left to wonder why having common norm is generally viewed as being negative and infringing on the rights of others. My experience has been that it is politically incorrect to advocate a single norm because it is regarded as being exclusionary or hierarchical. But what is wrong with having a common canon that can work to connect us? Does practicality not warrant that we have some common threads that bind us together and enable us to be able to reach consensus on the multiplicity of divisive issues that confront us? This further begs the question that in order for plurality to exist on a practical level, should there not be reasonable limits to pluralism? But then who will set those limits, and what will those limits be? Furthermore, limiting plurality means that the views of some individuals or groups may be left out and those of others may be given more importance. Is this not also leading to a situation of exclusion which is actually the true antithesis of plurality? In other words, does the quest to achieve a practical form of plurality actually foster exclusion rather than inclusion? By trying to capture and constrain plurality so that it can function on a workable level are we essentially doing more to undermine it? Therefore can a constrained form of pluralism be even called pluralism at all? However, how are we to deal with the apparently limitless nature of pluralism if we do not attempt to define it? This inevitably produces a vicious circular dilemma for which I have many questions but no clear answers.

Lastly, I am often confused by the mixed messages that are sent out by the Ministry of Education regarding what it believes about plurality and how it responds to it. On the surface the Ministry seems to promote the idea that plurality is an asset that needs to be nurtured and promoted. For example, government initiatives such as differentiated instruction and personalized learning are tools designed to enhance plurality. However, at the same time the government agenda of accountability seems to be moving in the opposite direction. Accountability initiatives such as the Foundation Skills Assessment or school performance contracts seem to be more of an 
attempt to standardize learning and teaching rather than diversify it. I believe that students and teachers are being corralled towards espousing a very specific and narrow view of education as a means to an economic end. How do school leaders reconcile this contradiction? Furthermore, are accountability measures doing more to drive teachers back towards familiar patterns (regress) rather than experiment with new ones?

As another school year comes to an end, I am brought back full circle and left reflecting on how effective I was in meeting the distinct needs of the twenty-five individual children who I worked with over the course of a short ten months. Although the diversity that they brought with them into my classroom was a challenge for me to cope with, I do not think I would have it any other way. As I grow in my practice I am coming to regard plurality as being an opportunity rather than a constraint. The challenge to respond to plurality keeps me rejuvenated as teacher who is constantly searching and learning for new ways to tame a condition that I am coming to realize cannot and should not be tamed. Rather than attempt to capture plurality in a box, I am coming to embrace it as a messy opportunity that will enable me to grow as a professional and refine my craft in an occupation which at its core is all about endless inquiry and learning.

\section{Reference:}

hooks, bell. (1994). Teaching to transgress: Education as the practice of freedom. Routledge: New York. 